\title{
Babesia spp. no líquido peritoneal em cão com ascite - relato de caso
}

\author{
Babesia spp. in the peritoneal fluid in dog with ascites - case report \\ J.M. Cota ${ }^{1}$, A.M.O. Orozco ${ }^{1}$, S.A.O. Bedoya ${ }^{1,2}$, A.C. Oliveira ${ }^{1}$, M.I.V. Viloria ${ }^{1}$, P.R.S. Costa ${ }^{1}$ \\ ${ }^{1}$ Universidade Federal de Viçosa - Viçosa, MG \\ ${ }^{2}$ Bolsista do Programa Estudantes-Convênio de Pós-Graduação - PEC-PG, CAPES/CNPq - Brasil.
}

\begin{abstract}
RESUMO
Babesia canis é um protozoário cosmopolita que parasita eritrócitos de cães domésticos e selvagens. O diagnóstico é realizado mediante a observação direta do microrganismo em hemácias no esfregaço de sangue periférico, métodos sorológicos e técnicas moleculares. O objetivo deste trabalho é relatar pela primeira vez a presença de merozoítos de Babesia spp. no líquido peritoneal de um cão com ascite. No Hospital Veterinário da Universidade Federal de Viçosa, foi atendido um cão, macho, sem raça definida, de sete meses de idade, com histórico de emaciação, apatia e abaulamento abdominal. No exame físico, foram evidenciadas mucosas hipocoradas, ascite, sopro sistólico grau IV/V e taquipneia. Nos exames laboratoriais, evidenciou-se anemia normocítica/normocrômica, trombocitopenia e hipoproteinemia. No esfregaço sanguíneo, foram observadas estruturas intraeritrocitárias compatíveis com Babesia spp. A avaliação do líquido ascítico foi compatível com transudato modificado e observaram-se inúmeras estruturas intra e extracelulares compatíveis com merozoítas de Babesia spp. A presença de microrganismos intra e extracelular poderia estar relacionada a uma lesão no baço com extravasamento do conteúdo para a cavidade abdominal. A coleta do líquido peritoneal pode ser uma alternativa para o diagnóstico de babesiose quando o animal com suspeita da infecção apresentar ascite.
\end{abstract}

Palavras-chave: cães, protozoário, líquido peritoneal, ascite

\begin{abstract}
Babesia canis is a cosmopolitan protozoan that parasites erythrocytes of domestic and wild dogs. The diagnosis is performed by direct observation of the microorganism in red blood cells in the peripheral blood smear, serological methods and molecular techniques. The aim of this work is to report for the first time the presence of merozoites of Babesia spp. in the peritoneal fluid of a dog with ascites. At the Veterinary Hospital of the Federal University of Viçosa was attended a Mixed-breed seven month old dog, male, with history of emaciation, apathy and abdominal bulging. Pale mucous membranes, ascites, grade IV/V systolic murmur and tachypnea were evidenced in the physical examination. Laboratory tests revealed normocytic/normochromic anemia, thrombocytopenia, and hypoproteinemia. Intra-erythrocyte structures compatible with Babesia spp. were observed in the blood smear. The evaluation of the ascites fluid was compatible with modified transudate where numerous intra and extracellular structures compatible with Babesia spp. merozoites were observed. The presence of intra and extracellular microorganisms could be related to an injury of the spleen with extravasation of the contents into the abdominal cavity. Collection of the peritoneal fluid may be an alternative for the diagnosis of babesiosis when the animal with suspected infection has ascites.
\end{abstract}

Keywords: dogs, protozoa, peritoneal fluid, ascites

Recebido em 16 de abril de 2017

Aceito em 10 de outubro de 2017

E-mail: jessmirandac@gmail.com 


\section{INTRODUÇÃO}

A babesiose canina é uma doença parasitária de importância clínica e distribuição mundial, que acomete caninos domésticos e selvagens (Irwin, 2010). É causada por protozoários do gênero Babesia, pertencente ao Phylum Apicomplexa, ordem Piroplasmida (Hunfield et al., 2008). No Brasil, a babesiose canina é causada, principalmente por $B$. canis vogeli e o vetor biológico é o carrapato marrom do cão Rhipicephalus sanguineus sensu lato, que também pode parasitar outros mamíferos (CostaJunior et al., 2009). Os esporozoítos estão presentes na glândula salivar do vetor e são transmitidos ao hospedeiro no momento da alimentação, infectando as hemácias. Nos eritrócitos, se tornam trofozoítos e se dividem por fissão binaria, produzindo merozoítos que serão liberados na circulação sanguínea, podendo infectar outras hemácias. Este processo ocorre até a morte do hospedeiro ou até que seu sistema imunológico controle a infecção, sendo o baço um órgão importante na remoção das células infectadas da circulação (Hunfield et al., 2008; Irwin, 2010). Nos animais doentes, são observados hematologicamente anemia e/ou trombocitopenia e alterações leucocitárias variadas, além de uma ampla variedade de sinais clínicos (Irwin, 2010). A severidade da doença pode variar desde uma infecção subaguda até o óbito por síndrome da disfunção múltipla de órgãos (Reddy et al., 2014). O diagnóstico é baseado na presença de inclusões de piroplasmas intraeritrocitários no esfregaço de sangue periférico. A parasitemia geralmente é baixa, o que dificulta a detecção do hematozoário por microscopia direta, sendo necessários outros métodos diagnósticos mais sensíveis, como a "detecção" ou o "exame" sorológico e molecular. (Costa-Júnior et al., 2009). O objetivo deste trabalho é relatar pela primeira vez a presença de merozoítos de Babesia spp. no líquido peritoneal de um cão.

\section{RELATO DE CASO}

Foi atendido, no Hospital Veterinário da Universidade Federal de Viçosa, um canino, macho, sem raça definida, sete meses de idade, com queixa de, havia três semanas apresentar emaciação, apatia e distensão abdominal. Foram relatados também cansaço fácil e presença de carrapatos.

Ao exame físico, as mucosas estavam pálidas e o paciente se encontrava apático. À ausculta cardiopulmonar, foi notado sopro sistólico grau IV/V, em foco tricúspide e mitral. O abdômen se encontrava distendido, com balotamento positivo. Apresentava-se com taquipneia. A saturação de oxigênio se manteve em valores superiores a $90 \%$ de $\mathrm{O}_{2}$. A pressão arterial sistólica pelo método Doppler foi de $150 \mathrm{mmHg}$. Demais parâmetros fisiológicos estavam dentro dos valores de normalidade.

Realizou-se paracentese abdominal guiada pela ultrassonografia e foram drenados $500 \mathrm{~mL}$ de líquido ascítico sanguinolento e de aspecto turvo. O paciente foi submetido aos seguintes exames: hemograma completo, ureia, creatinina, ALT (alanina aminotransferase), AST (aspartato aminotransferase), FA (fosfatase alcalina), proteína total, albumina, globulina, glicose, cálcio, fósforo, cloreto, sódio, potássio (Tab. 1), urinálise (Tab. 2) e análise de líquido peritoneal. O hemograma evidenciou anemia normocítica normocrômica. Na pesquisa de hematozoários no sangue, foram observadas inclusões basofílicas intraeritrocitárias compatíveis com Babesia spp. em pouca quantidade (Fig. 1).

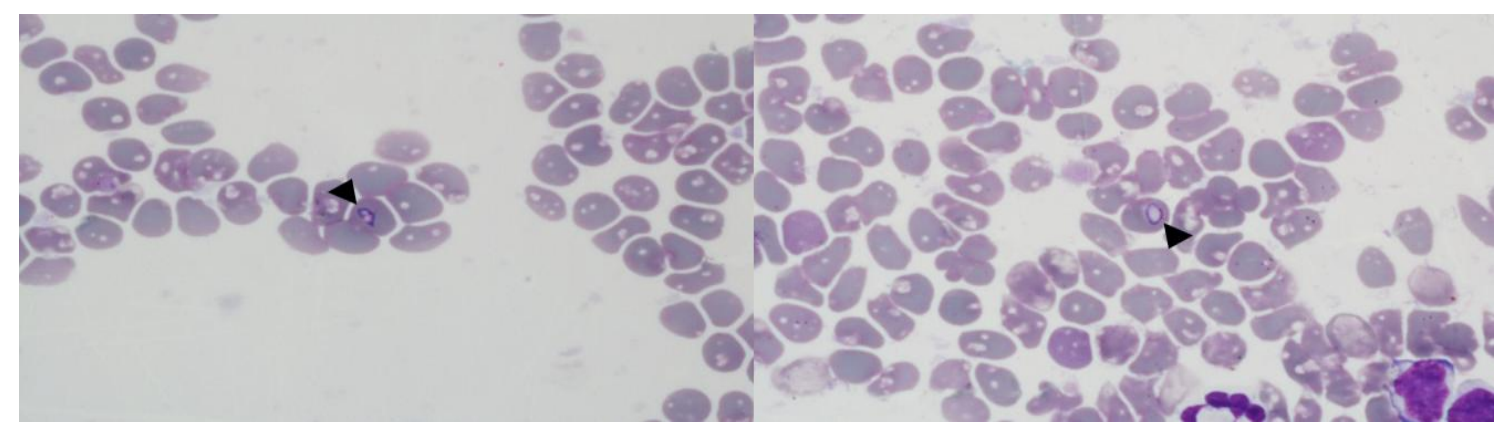

Figura 1. Fotomicrografia de esfregaço sanguíneo mostrando a presença de merozoítos de Babesia spp. intraeritrocitários (cabeça de seta), Panótico, 1000x. 
Babesia spp. no líquido...

Tabela 1. Resultados do eritrograma completo com contagem plaquetária, leucograma e perfil bioquímico do cão com babesiose realizados durante o atendimento.

\begin{tabular}{|c|c|c|}
\hline \multicolumn{3}{|c|}{ Eritrograma } \\
\hline Analito & Valor & Valores de referência \\
\hline Hemácias $\left(\times 10^{6} / \mu \mathrm{L}\right)$ & 4,17 & $5,5-8,5$ \\
\hline Hemoglobina $(\mathrm{g} / \mathrm{dL})$ & 8,9 & $12-18$ \\
\hline Hematócrito (\%) & 25,6 & $37-55$ \\
\hline Proteína total $(\mathrm{g} / \mathrm{dL})$ & 5,4 & $5,7-7,0$ \\
\hline VCM $(\mathrm{fl})$ & 61,4 & $60-77$ \\
\hline $\mathrm{HCM}(\mathrm{pg})$ & 21,3 & $19,5-24,5$ \\
\hline $\mathrm{CHCM}(\%)$ & 34,7 & $30-36$ \\
\hline \multicolumn{3}{|c|}{ Leucograma } \\
\hline Leucócitos / $\mu \mathrm{L}$ & 13.200 & $6.000-17.000$ \\
\hline Segmentados $/ \mu \mathrm{L}$ & 8712 & $3.000-11.500$ \\
\hline Bastonetes $/ \mu \mathrm{L}$ & 396 & $0-300$ \\
\hline Linfócitos $/ \mu \mathrm{L}$ & 3168 & $1.000-4.800$ \\
\hline Eosinófilos $/ \mu \mathrm{L}$ & 528 & $100-1.250$ \\
\hline Monócitos / $\mu \mathrm{L}$ & 396 & $150-1.350$ \\
\hline Basófilos / $/ \mu \mathrm{L}$ & 0 & Raros \\
\hline Plaquetas $/ \mu \mathrm{L}$ & 76000 & $175.000-500.000$ \\
\hline \multicolumn{3}{|c|}{ Bioquímico } \\
\hline Ureia (mg/dL) & 80,6 & $21-59,9$ \\
\hline Creatinina $(\mathrm{mg} / \mathrm{dL})$ & 0,95 & $0,5-1,5$ \\
\hline ALT-GPT (U/L) & 10 & $21-102$ \\
\hline AST -GOT (U/L) & 37 & $23-66$ \\
\hline FA $(\mathrm{U} / \mathrm{L})$ & 102 & $20-156$ \\
\hline Prot. total & 4,2 & $5,4-7,1$ \\
\hline Albumina $(\mathrm{g} / \mathrm{dL})$ & 2,25 & $2,6-3,3$ \\
\hline Globulina $(\mathrm{g} / \mathrm{dL})$ & 1,95 & $2,7-4,4$ \\
\hline Glicose $(\mathrm{mg} / \mathrm{dL})$ & 102 & $65-112$ \\
\hline Cálcio (mg/dL) & 10,2 & $9,0-11,3$ \\
\hline Fósforo (mg/dL) & 9,7 & $2,6-6,2$ \\
\hline Cloreto $(\mathrm{mmol} / \mathrm{L})$ & 108,1 & $105-115$ \\
\hline
\end{tabular}

Fonte dos valores de referência: Thrall, 2007.

Tabela 2. Resultados da urinálise do cão com babesiose realizados durante o atendimento.

\begin{tabular}{cc}
\hline & Análise física \\
\hline Volume: $5 \mathrm{~mL}$ & Cor: amarelo-claro \\
\hline Densidade: 1,019 & Aspecto: turvo \\
\hline Proteína: $+/ 4$ & Análise química \\
\hline Corpos cetônicos: negativo & Sangue: negativo \\
\hline Leucócitos: negativo & Bilirrubina: negativo \\
\hline Glicose: negativo & Urobilinogênio: normal \\
\hline \multicolumn{3}{c}{ Análise do sedimento } \\
\hline Cls. de descamação: células de transição escassas \\
\hline \multicolumn{2}{c}{ Cristais: uratos amorfos +/4 } \\
\hline Leucócitos por campo: raros \\
\hline Hemácias por campo: ausentes \\
\hline Muco: escasso & Espermatozoides: ausentes \\
\hline Flora bacteriana: ausente
\end{tabular}


O líquido peritoneal apresentava aspecto turvo, coloração avermelhada, densidade 1.025, proteína 2,8g/dL, com contagem global de células nucleadas de $3400 / \mu \mathrm{L}$, com presença de neutrófilos (58\%), linfócitos (24\%), monócitos
(17\%) e eosinófilos (1\%). Foram observados inúmeros merozoítos de Babesia spp. (Fig. 2). A análise foi compatível com transudato modificado.

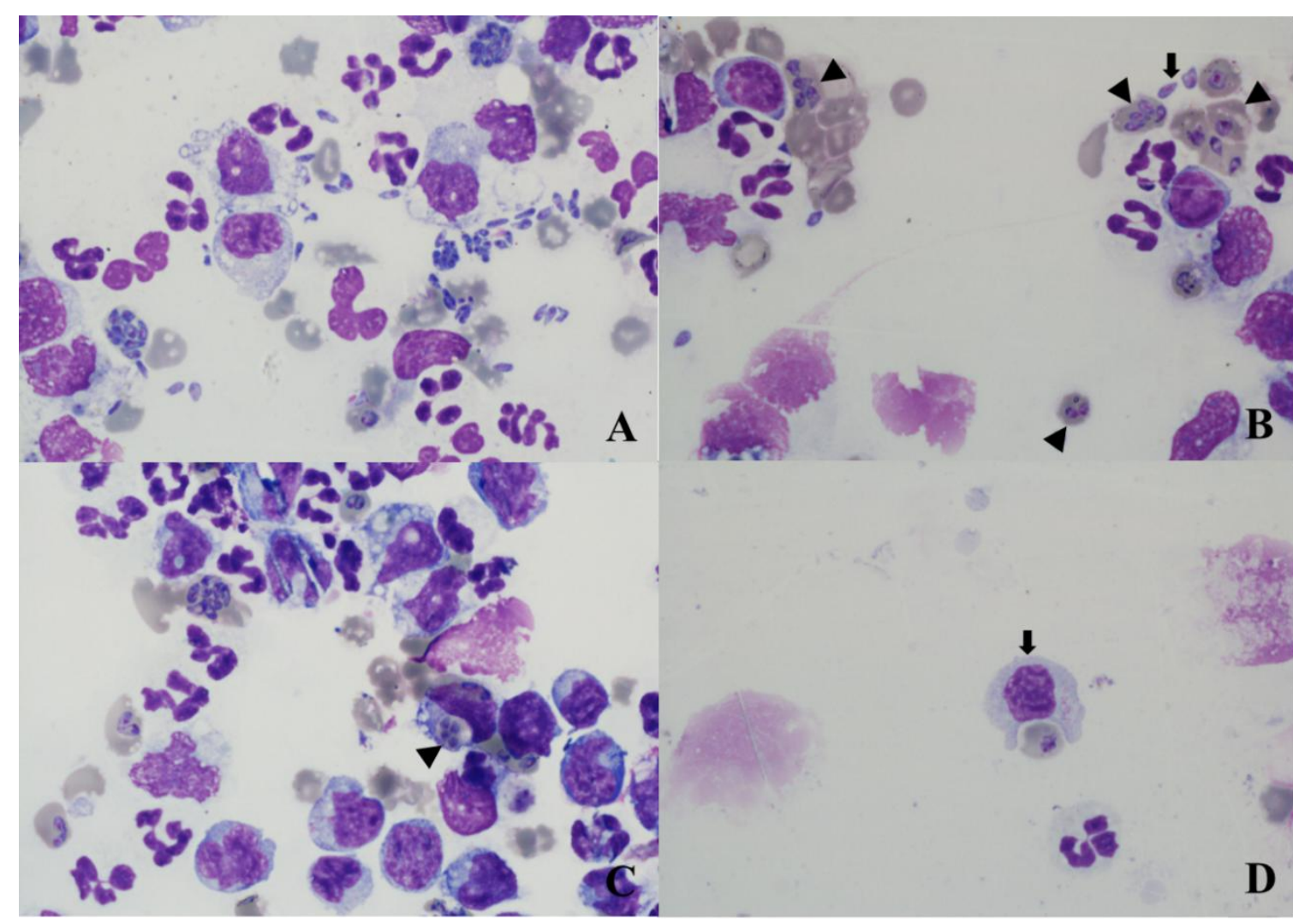

Figura 2. Fotomicrografia de esfregaço do líquido peritoneal, classificado como transudato modificado. A) Observa-se a presença de macrófagos, neutrófilos e inúmeros merozoítos de Babesia spp. B) Merozoítos de Babesia spp. intra (cabeça de seta) e extracelulares (seta). C) Macrófago com merozoítos no citoplasma, evidenciando eritrofagia (cabeça de seta). D) Macrófago formando os pseudópodos para fagocitar uma hemácia parasitada (seta). Panótico, 1000x.

Realizou-se tratamento com dipropionato de imidocarb, na dose de $5 \mathrm{mg} / \mathrm{kg}$, e doxiciclina $10 \mathrm{mg} / \mathrm{kg}$, a cada 24 horas, por 28 dias. Entretanto, o paciente veio a óbito cinco dias após o atendimento, em decorrência de comorbidades (cardiopatia).

\section{DISCUSSÃO}

No presente caso, observou-se grande quantidade de merozoítos de Babesia spp. na análise citológica do líquido peritoneal. Este achado permitiu chegar ao diagnóstico de babesiose, de um modo inusitado, já que tradicionalmente se encontra Babesia spp. na avaliação do esfregaço sanguíneo. Lesões esplênicas associadas ao processo infeccioso (esplenomegalia, infarto) poderiam resultar em extravasamento de sangue para o peritônio (Trotta et al., 2009), justificando a presença do protozoário em forma intra e extracelular nesse espaço. A efusão peritoneal associada à infecção por Babesia gibsoni foi relatada em cães, entretanto o diagnóstico baseou-se na identificação do agente no esfregaço de sangue periférico da ponta da orelha, sendo confirmado por PCR, sem a visualização de merozoítos no líquido peritoneal (Gonde et al., 2014). 
O baço é um órgão importante no controle da babesiose quanto à remoção de hemácias parasitadas da circulação. As hemácias parasitadas apresentam alterações na membrana celular que diminuem sua vida média na circulação, tornando-as mais susceptíveis à hemólise extravascular pelo sistema fagocítico mononuclear do baço, sendo o sequestro esplênico uma possível hipótese para a baixa carga parasitária no sangue (Hunfeld et al., 2008), o que dificultou a visualização dos merozoítos de Babesia spp. esfregaço sanguíneo.

A hipoalbuminemia, o aumento da permeabilidade capilar e uma provável insuficiência cardíaca congestiva direita (ICCD) por cardiopatia congênita poderiam justificar a presença da ascite neste caso, porém não houve definição do quadro cardiológico porque $o$ paciente veio a óbito antes de exames mais específicos. No entanto, lesões cardíacas têm sido relatadas como achados incidentais no exame post mortem em casos de babesiose e são consideradas uma complicação rara (Lobetti, 2005). As lesões cardíacas secundárias à babesiose se desenvolvem por uma resposta inflamatória devido à hipóxia anêmica. Os ventrículos são os mais acometidos, principalmente o ventrículo esquerdo, com lesões cardíacas macroscópicas, incluindo derrame pericárdico e hemorragias pericárdicas, epicárdicas e endocárdicas (Lobetti, 2005).

A ocorrência de cães soropositivos a babesiose canina no Brasil varia entre 35,8 a $67 \%$ dependendo da região estudada, sendo a doença endêmica e a infecção subclínica predominante, justificando, portanto, a ausência de sinais clínicos em alguns cães doentes (Vidotto e Trapp, 2004). Os sinais clínicos comumente observados são febre, apatia e mucosas hipocoradas (Vilela et al., 2013). Achados clínicos semelhantes aos apresentados pelo paciente no momento do exame físico, sem a presença de febre.

No presente caso, observou-se anemia normocítica normocrômica e trombocitopenia acentuada, sem alterações leucocitárias. Os achados foram similares ao encontrado por Vilela e colaboradores (2013), em um estudo realizado no município de Seropédica, Rio de Janeiro, sendo que eles relataram trombocitopenia discreta em $81,1 \%$ dos cães avaliados. Apesar de ser relatada somente a presença de Babesia spp. na pesquisa de hematozoários no esfregaço sanguíneo, não se exclui a possibilidade de coinfecção com outros microrganismos transmitidos por carrapatos que também podem apresentar esses achados laboratoriais, como Ehrlichia canis, Anaplasma platys, entre outros (Yabsley et al., 2008).

As principais alterações bioquímicas neste caso clínico foram hipoproteinemia por hipoalbuminemia e hipoglobulinemia, achados similares ao reportado na literatura para alguns casos de babesiose em cães (Reddy et al., 2014; Gonde et al., 2014). A hipoalbuminemia pode ser decorrente à diluição do volume intravascular por retenção de líquidos no espaço extracelular ou devido a albumina ser uma proteína de fase aguda negativa, justificando portanto sua concentração sérica diminuída neste caso (Lobetti, 2005).

Diante da literatura consultada, não foram encontrados dados referentes ao achado de merozoítos de Babesia spp. no líquido peritoneal, portanto o relato do presente caso permite incluir o exame de líquido peritoneal como uma opção diagnóstica para babesiose em pacientes com a doença e apresentação clínica de ascite.

\section{AGRADECIMENTOS}

Os autores agradecem ao Hospital Veterinário da UFV, à Capes, à Fapemig e ao CNPq.

\section{REFERÊNCIAS}

COSTA-JÚNIOR, L.M.; RIBEIRO M.F.; REMBECK K. et al. Canine babesiosis caused by Babesia canis vogeli in rural areas of the State of Minas Gerais, Brazil and factors associated with its seroprevalence. Res. Vet. Sci., v.86, p.257-260, 2009.

GONDE, S.; CHHABRA, S.; SINGLA, L.D.; BANSAL, B.K. Peritoneal effusion in a dog due to Babesia gibsoni infection. Case Rep. Vet. Med., v.2014, p.1-4, 2014.

HUNFELD, K.P.; HILDEBRANDT, A.; GRAY, J.S. Babesiosis: recent insights into an ancient disease. Int. J. Parasitol., v.38, p.1219-1237, 2008. 
IRWIN, P.J. Canine babesiosis. Vet. Clin. N. Am. Small Anim. Pract., v.40, p.141-1156, 2010.

LOBETTI, R.G. Cardiac involvement in canine babesiosis. J. S. Afr. Vet. Assoc., v.76, p.4-8, 2005.

REDDY, B.S.; SIVAJOTHI, S.; REDDY, L.S.S.V.; RAJU, K.G.S. Clinical and laboratory findings of Babesia infection in dogs. J. Parasit. Dis., v.40, p.268-272, 2014.

THRALL, M.A. Hematologia e bioquímica clínica veterinária. São Paulo: Roca, 2007. 582p.

TROTTA, M.; CARLI E.; NOVARI, G.L. et al. Clinicopathological findings, molecular detection and characterization of Babesia gibsoni infection in a sick dog from Italy. Vet. Parasitol., v.165, p.318-322, 2009.
VIDOTTO, O.; TRAPP, S.M. Babesiose canina. Rev. Bras. Parasitol. Vet., v.13, suplemento 1, p. 58-61, 2004

VILELLA, J.A.R.; PIRES, M.S.; SILVA C.B. et al. Alterações clínico-hematológicas da infecção por Babesia canis vogeli em cães do município de Seropédica, Rio de Janeiro, Brasil. Rev. Bras. Med. Vet., v.35, p.63-68, 2013.

YABSLEY, M.J.; MCKIBBEN, J.; MACPHERSON, C.N. et al. Prevalence of Ehrlichia canis, Anaplasma platys, Babesia canis vogeli, Hepatozoon canis, Bartonella vinsonii berkhoffii, and Rickettsia spp. in dogs from Grenada. Vet. Parasitol., v.151, p.279-285, 2008. 